Copyright $\odot 2017$ The Author(s). Published by BCS, The Chartered Institute for IT under Creative Commons license http://creativecommons.org/ licenses/by/4.0/

\section{In this issue: innovation in design and implementation in health informatics}

\author{
Simon de Lusignan \\ Professor of Primary Care \& Clinical Informatics, University of Surrey, Guildford, UK \\ Editor-in-Chief Journal of Innovation in Health Informatics
}

\section{INFORMATICS TO SUPPORT NATIONS THAT ARE LESS RESOURCE RICH}

In this issues provides evidence that good design can facilitate implementation. However, this issue also continues an ongoing theme that we must not make assumptions about the effectiveness of IT; as scientists, we should continually question and challenge. ${ }^{1}$

Our first paper explores how careful planning is needed to implement computerised medical records (CMR) in less resource rich countries. Our first paper describes how the open source Bahami system (https://www.bahmni.org/, a front end for OpenMRS http://openmrs.org/) has been implemented in Nepal. ${ }^{2}$ Our next paper also looks at the less resource rich, but this time how IT systems in community health facilities might help low-income individuals and families avoid potentially disastrous gaps in their public health insurance. ${ }^{3}$

\section{PROS AND CONS OF THE COMPUTER IN THE CONSULTATION}

Compeau and Terry describe how, even though it has shortcomings, health information exchange has benefits for primary care. A challenge with such studies is the risk of selection bias with a low response rate $(<50 \%)$. Notwithstanding the study usefully catalogues benefits and challenges. ${ }^{4}$ Our next study reports how the top concern of CMR users is that it interferes with their relationship with the patients - with a marvellous quote 'It is like texting at the dinner table'. ${ }^{5}$ This study is congruent with your editor's observations from many video studies; the computer interferes with the doctor-patient relationship but there are tradeoffs! ${ }^{6} \mathrm{~A}$ systematic review, published within the pages of this journal, reported positive biomedical features of CMR use, ${ }^{7}$ though its impact on relationships was more negative. ${ }^{8}$

\section{QUESTIONING THE RELIABILITY AND VALIDITY OF TECHNOLOGIES}

Parpinel et al. test different methods of heart rate monitoring on different mobile phone platforms against a gold standard monitor. This is a simple but very useful challenge to the assumption that mobile devices accurately measure vital signs. ${ }^{9}$ Similarly, Shaw and McGuire's review of geographic information system technology concludes that improvements need to be made in the quality of data input if proper conclusions are going to be made from the use of these technologies. ${ }^{10}$ Hagger-Johnson et al. looked at the pseudonymisation algorithm ${ }^{11}$ used in the English NHS to link together hospital and other data. This approach to pseudonymisation has never been 
reviewed and is topical because pseudonymisation is included within the new EU Data Protection Regulation in 2016 as a privacy protecting measure. ${ }^{12}$ They found gaps with marked disparities and suggest how these might be reduced. ${ }^{13}$ Our Editorial follows this theme. Bond challenges the assumption in the Autumn BCS publication IT Now that technology should stream data towards clinicians (many of whom are already overworked) instead of using it to foster self-management support. ${ }^{14}$ Streaming big data towards your family physician may be some peoples' utopia, but is more likely to represent dystopia (Oxford English definition: an imagined place or state in which everything is unpleasant or bad).

\section{REFERENCES}

1. de Lusignan S. In this issue - Don't make assumptions about integrated systems, data quality, utilisation of technology, or access to routine data. Journal of Innovation in Health Informatics. 2016;23(3):911. doi: 10.14236/jhi.v23i3.911.

2. Raut A, Yarbrough C, Singh V, Gauchan B, Citrin D, Verma V, et al. Design and implementation of an affordable, public sector electronic medical record in rural Nepal. Journal of Innovation in Health Informatics. 2017;24(2):186-195. Available at: http://dx.doi.org/10.14236/jhi.v24i2.862.

3. Hall JD, Harding RL, DeVoe JE, Gold R, Angier H, Sumic A, et al. Designing health information technology tools to prevent gaps in public health insurance. Journal of Innovation in Health Informatics. 2017;24(2):196-203. Available at: http://dx.doi. org/10.14236/jhi.v24i2.900.

4. Compeau DR and Terry AL. Connecting medical records: an evaluation of benefits and challenges for primary care practices. Journal of Innovation in Health Informatics. 2017;24(2):204215. Available at: http://dx.doi.org/10.14236/jhi.v24i2.855.

5. Pelland KD, Baier RR and Gardner RL. 'It is like texting at the dinner table': a qualitative analysis of the impact of electronic health records on patient-physician interaction in hospitals. Journal of Innovation in Health Informatics. 2017;24(2): 216-223. Available at: http://dx.doi.org/10.14236/jhi.v24i2.884.

6. Kumarapeli $P$ and de Lusignan $S$. Using the computer in the clinical consultation; setting the stage, reviewing, recording, and taking actions: multi-channel video study. Journal of the American Medical Informatics Association 2013;20(e1):e6775. doi: 10.1136/amiajnl-2012-001081.

7. Kazmi Z. Effects of exam room EHR use on doctor-patient communication: a systematic literature review. Informatics in Primary Care 2013;21(1):30-39. doi: 10.14236/jhi.v21i1.37.

8. Pearce CM, Kumarapeli $P$ and de Lusignan $S$. "Effects of exam room EHR use on doctor-patient communication: a systematic literature review" - triadic and other key terms may have identified additional literature. Informatics in Primary Care 2013;21(1):40-42. doi: 10.14236/jhi.v21i1.39.

9. Parpinel M, Scherling L, Lazzer $S$ and Della Mea V. Reliability of heart rate mobile apps in young healthy adults: exploratory study and research directions.

\section{SUPPORTING TECHNOLOGY WITH IMPACT}

Cresswell et al. describe how their electronic prescribing toolkit has been used and had impact. In a survey with a $60 \%$ response rate, $92 \%$ were familiar with their toolkit and $66 \%$ reported using it. Whist it can be argued that evaluation should be independent, ${ }^{15}$ and the overwhelmingly positive response is reassuring. There were suggestions for improving the toolkit, and this illustrates the impact and importance of literature to support technology. ${ }^{16}$ Finally, we publish a letter from Gofine and Clark proposing the use of Slack team messaging platform in research groups. ${ }^{17}$

Journal of Innovation in Health Informatics. 2017;24(2): 224-227. Available at: http://dx.doi.org/10.14236/jhi.v24i2.921.

10. Shaw NT and McGuire SK. Understanding the use of geographical information systems (GISs) in health informatics research: a review. Journal of Innovation in Health Informatics. 2017;24(2):228-233. Available at: http://dx.doi.org/10.14236/ jhi.v24i2.940.

11. de Lusignan S. Effective pseudonymisation and explicit statements of public interest to ensure the benefits of sharing health data for research, quality improvement and health service management outweigh the risks. Informatics in Primary Care 2014;21(2):61-63. doi: 10.14236/jhi.v21i2.68.

12. Chan $T$, Di lorio $C T$, De Lusignan $S$, Lo Russo D, Kuziemsky $C$ and Liaw ST. UK National Data Guardian for Health and Care's Review of Data Security: trust, better security and opt-outs. Journal of Innovation in Health Informatics. 2016;23(3):627-32. doi: 10.14236/jhi.v23i3.909.

13. Hagger-Johnson G, Harron K, Goldstein H, Aldridge R and Gilbert R. Probabilistic linking to enhance deterministic algorithms and reduce linkage errors in hospital administrative data. Journal of Innovation in Health Informatics. 2017;24(2):234246. Available at: http://dx.doi.org/10.14236/jhi.v24i2.891.

14. Bond CS. Healthcare utopia or dystopia: empowering improved self-management may be a better role for technology. Journal of Innovation in Health Informatics. 2017;24(2):255-256. Available at: http://dx.doi.org/10.14236/jhi.v24i2.943.

15. Moore GF, Audrey S, Barker M, Bond L, Bonell C, Hardeman W, et al. Process evaluation of complex interventions: Medical Research Council guidance. BMJ 2015;350:h1258. doi: 10.1136/bmj.h1258.

16. Cresswell K, Slee A and Sheikh A. A survey exploring National Health Service ePrescribing Toolkit use and perceived usefulness amongst English hospitals. Journal of Innovation in Health Informatics. 2017;24(2):247-251. Available at: http://dx.doi. org/10.14236/jhi.v24i2.905.

17. Gofine M and Clark S. Integration of Slack, a cloud-based team collaboration application, into research coordination. Journal of Innovation in Health Informatics. 2017;24(2):252-254. Available at: http://dx.doi.org/10.14236/jhi.v24i2.936. 